\title{
Oral Kaposi sarcoma development is associated with HIV viral load, CD4+ count and CD4+/CD8+ ratio
}

\author{
Rosa Hiolanda Abreu de Sousa ${ }^{1,2}$, Lucas Lacerda de Souza ${ }^{1,2}$, Pablyanne Tereza Louzada Guedes ${ }^{1,2}$, Ana \\ Carolina Prado-Ribeiro ${ }^{1,3}$, Leticia Rodrigues-Oliveira ${ }^{1}$, Thaís Bianca Brandão ${ }^{3}$, Barbara Waleria Gonçalves \\ Alves ${ }^{2}$, Márcio Ajudarte Lopes ${ }^{1}$, Alan Roger Santos-Silva ${ }^{1}$, Julius Caesar Mendes Soares Monteiro ${ }^{4}$, Thaís \\ Tapajós Gonçalves ${ }^{5}$, Oslei Paes de Almeida ${ }^{1}$, Flavia Sirotheau Correa Pontes ${ }^{2}$, Hélder Antônio Rebelo Pontes ${ }^{1,2}$
}

${ }^{1}$ Oral Diagnosis Department (Pathology and Semiology), Piracicaba Dental School University of Campinas (UNICAMP), Brazil

${ }^{2}$ Oral Pathology Department, João de Barros Barreto University Hospital (JBBUH), Federal University of Pará (UFPA), Belém, Brazil

${ }^{3}$ Dental Oncology Service, Instituto do Câncer do Estado de São Paulo (ICESP-FMUSP), Brazil

${ }^{4}$ Infectious and Parasitic Diseases Department, João de Barros Barreto University Hospital (JBBUH), Federal University of Pará (UFPA), Belém, Brazil

${ }^{5}$ General Surgery Department, João de Barros Barreto University Hospital (JBBUH), Federal University of Pará (UFPA), Belém, Brazil

Correspondence:

João de Barros Barreto University Hospital

Department of Surgery and Oral Pathology

Mundurucus Street, $n^{\circ} 4487$

Zip Code 66073-000, Belém, Pará, Brazil

harp@ufpa.br

Sousa RH, Souza LL, Guedes PT, Prado-Ribeiro AC, Rodrigues-Oliveira L, Brandão TB, et al. Oral Kaposi sarcoma development is associated with HIV viral load, CD4+ count and CD4+/CD8+ ratio. Med Oral Patol Oral Cir Bucal. 2021 Nov 1;26 (6):e748-53.

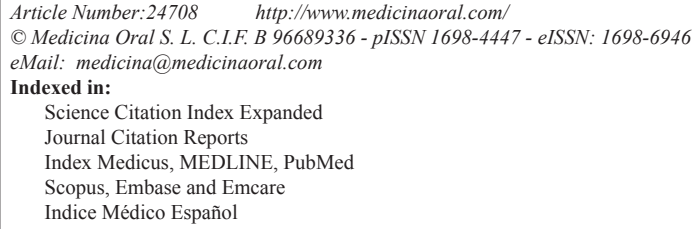

\begin{abstract}
Background: Kaposi's sarcoma (KS) is an uncommon, multifocal and angioproliferative lesion, which demonstrates a poor prognosis. The aim of the present research was to explore the association of HIV viral load, CD4+ and CD8+ counts and the CD4+/CD8+ ratio on the risk of oral Kaposi's sarcoma (KS) development.

Material and Methods: A total of 62 patients were retrieved from March 2008 to October 2020 from the files of two oral pathology centres. Clinical, laboratory and follow-up data were retrieved from their medical files. Poisson regression was used to explore the role of history of immunosuppression and its association with oral KS development. A P-value $<0.05$ was considered significant.

Results: Sixty-two patients were included in the present study (32 with oral KS and 30 with no presentation of lesions anywhere on the body). Patients with oral KS presented a mean age of 32.6 years, and male patients were more affected. The hard palate (15 cases; $46.8 \%)$ was the main anatomical site affected. The lesions were mostly presented as swellings (13 cases; 40.6\%) and nodules (12 cases; 37.5\%). Systemic manifestations were also observed, including candidiasis (4 cases; 12.5\%), bacterial infection ( 3 cases; 9.3\%), tuberculosis ( 3 cases; 9.3\%), herpes simplex (3 cases; 9.3\%) and pneumonia (3 cases; 9.3\%). A significant correlation was observed between HIV viral load, CD4+ count and the CD4+/CD8+ ratio with oral KS development.

Conclusions: HIV viral load, CD4+ count and the CD4+/CD8+ ratio are associated with oral KS development.
\end{abstract}

Key words: Cancer, oral, Kaposi's sarcoma, diagnostic. 


\section{Introduction}

Kaposi's sarcoma (KS) is an uncommon, multifocal, angioproliferative lesion initially described by Moritz Kaposi in $1872(1,2)$. The tumour is formed by the endothelial cells of blood and lymphatic vessels and shows a variety of clinical, epidemiological and immunophenotypic characteristics $(3,4)$. KS was classified epidemiologically by Antman and Chang in 2000: 1) the classic form occurs in middle-aged or elderly patients, 2) the endemic type is presented in Sub-Saharan Africa, 3) the epidemic category is AIDS associated and 4) the iatrogenic type is related to immunosuppression in patients receiving anti-rejection therapy for transplanted organs $(5,6)$. The aetiology of KS is associated with human herpesvirus-8 (HHV8) in all epidemiologic subtypes of the lesion $(7,8)$.

$\mathrm{KS}$ is recognized as an AIDS-defining cancer, along with non-Hodgkin's lymphoma and invasive cervical cancer $(3,8,9)$. Clinically, lesions may be presented in the skin, oral mucosa, gastrointestinal tract, lymph nodes and lungs $(8,10)$. When the oral cavity is affected, lesions can demonstrate a variable morphology, from plaques to swellings with a purple or dark-brown appearance $(6,11,12)$. In addition, KS was identified as the second most common sarcoma of the oral cavity according to a multicentre study of oral sarcomas in the Brazilian population (11).

The prognosis for people living with HIV/AIDS (PLWHA) improved with the initiation of highly active antiretroviral therapy (HAART) in the mid ' 90 s (13-15). Despite significant advances in KS therapy, the innate immune system do not contributes significantly to treatment effectiveness (3-5). HIV viral load (HVL), CD4+ (CD4L) and CD8+ (CD8L) levels and the CD4+/CD8+ $(\mathrm{CD} 4 \mathrm{~L} / \mathrm{CD} 8 \mathrm{~L})$ ratio are all very important in the assessment of the patients' systemic condition $(8,10,16,17)$.

According to previous literature, the association of patients' systemic condition and the development of oral KS has not been well established. Thus, the objective of this study is to evaluate the association of HVL, CD4L and CD8L and the CD4L/CD8L ratio with the development of oral KS.

\section{Material and Methods}

- Study design and ethical approval

This research was developed on the files from two oral pathology centres of Brazil. Samples were retrieved from the centres over a period of 12 years (from March 2008 to October 2020). The diagnosis centres were João de Barros Barreto University Hospital, Federal University of Pará, Belém/Brazil and Instituto do Câncer do Estado de São Paulo (ICESP-FMUSP), São Paulo/ Brazil. Expert oral pathologists from each centre evaluated the samples. The ethics committee of the João de Barros Barreto University Hospital approved this work
(No. 3.952.288). The patients' identities remained anonymous according to the Declaration of Helsinki.

- Samples

Patients from both control and KS groups were retrieved based on the initial diagnosis of HIV/AIDS. KS in the oral cavity were recovered, and data regarding sex, age, location, clinical aspects, HIV/KS diagnosis and laboratory findings (HVL, CD4L, CD8L and CD4L/CD8L) were retrieved. Ranges of laboratory findings were classified following Taiwo \& Hassan (2010), following: HIV viral load was ranged as $<20,20 \leq 199,200 \leq 999$ and $>999$ copies/mL; CD4+ as $\leq 200,201-499$ and $\geq 500$ cells/mm3; CD8+ as $\leq 150,150-1000$ and $>1000$ cells/ $\mathrm{mm} 3$; $\mathrm{CD} 4+/ \mathrm{CD} 8+$ ratio was considered according to the mean values of all patients (18). In cases that oral KS was not confirmed, when patients refused to participate the research and when laboratory tests were not assessed represented the exclusion criteria. Lesions were diagnosed following the methods of our study group (19). For better illustration, all cases were also stained with CD34, D2-40 (podoplanin) and Prox-1.

- Data analysis

Means and percentages are presented as descriptive statistics. Poisson regression was used to explore the role of the prevalence of immunosuppression and the association of oral KS development, exploring HVL, CD4L, $\mathrm{CD} 8 \mathrm{~L}$ and $\mathrm{CD} 4 \mathrm{~L} / \mathrm{CD} 8 \mathrm{~L}$ ratio. A $P$-value $<0.05$ was considered statistically significant. Data were analysed using IBM SPSS Statistics for Windows, version 23.0 (Armonk, NY).

\section{Results}

A total of $62 \mathrm{HIV}$-positive patients, including $32 \mathrm{pa}-$ tients with clinical presentation of oral KS and 30 patients with no KS lesions on the body were included in this research.

Regarding patients with oral KS, a mean age of 32.6 years (range of 19-58 years old) was observed. Male patients were mostly affected, with a M:F ratio of 10.6:1. The hard palate ( 15 cases; $46.8 \%$ ) was the main location of the lesion, followed by the alveolar ridge ( 6 cases; $18.7 \%$ ), soft palate ( 6 cases; $18.7 \%$ ), tongue ( 5 cases; $15.6 \%)$ and gums (5 cases; $15.6 \%)$. The mandible (2 cases; 6.2\%), maxilla (1 case; $3.1 \%)$, lower lip (1 case; $3.1 \%$ ) and upper lip (1 case; 3.1\%) were less frequently affected. Lesions were presented as swellings (13 cases; $40.6 \%$ ), nodules (12 cases; 37.5\%), plaques (5 cases; $15.6 \%$ ) and spots ( 2 cases; $6.2 \%$ ). They showed purple (53.1\%) and red colouration (15 cases; 46.8\%) (Fig. 1). In addition, oral KS showed bleeding in 15 cases $(46.8 \%)$ and pain in 14 cases $(43.7 \%)$. The lesions were the first manifestation of HIV/AIDS in 23 cases $(71.8 \%)$. Patients also showed lesions in the skin (10 cases; $31.2 \%)$, intestine ( 4 cases; $12.5 \%$ ), stomach ( 4 cases; $12.5 \%$ ), trachea ( 3 cases; 9.3\%), lung ( 3 cases; 9.3\%), eyes (1 case; 
$3.1 \%$ ) and pharynx (1 case; 3.1\%). Systemic comorbidities were observed in 16 cases $(50 \%)$ and oral candidiasis ( 4 cases; $12.5 \%$ ), bacterial infection ( 3 cases; 9.3\%), tuberculosis (3 cases; 9.3\%), oral herpes simplex (3 cases; $9.3 \%$ ), pneumonia ( 3 cases; $9.3 \%$ ), gastroenteritis (2 cases; 6.2\%), syphilis ( 2 cases; $6.2 \%$ ) and meningitis (2 cases; $6.2 \%$ ) were most often seen.

Histopathological findings showed fascicular arrangement of spindle cells and extravasation of red blood cells. It was also observed blood filled slits like spaces, spindle shaped cells with prominent pleomorphism. Immunohistochemistry reactions were positive for CD34, D2-40, Prox-1 and HHV-8 in situ hybridization (Fig. 2).

The control group had a mean age of 41.6 years (range of 25-61 years), and male patients were more frequently affected than females, with a M:F ratio of 1.3:1. Oral manifestation was observed in 5 patients $(16.6 \%)$, and candidiasis ( 3 cases; 10\%), oral herpes ( 2 cases; $6.6 \%$ ) and hairy leukoplakia (1 case; $3.3 \%$ ) were the manifestations seen. Systemic comorbidities were observed in all cases, and tuberculosis (14 cases; 46.6\%), meningitis (5 cases; 16.6\%), neurotoxoplasmosis (5 cases; 16.6\%), bacterial infection (4 cases; 13.3\%), scabies ( 2 cases; $6.6 \%$ ), pneumopathy (2 cases; 6.6\%) and syphilis (2 cases; $6.6 \%$ ) were the main presentations.
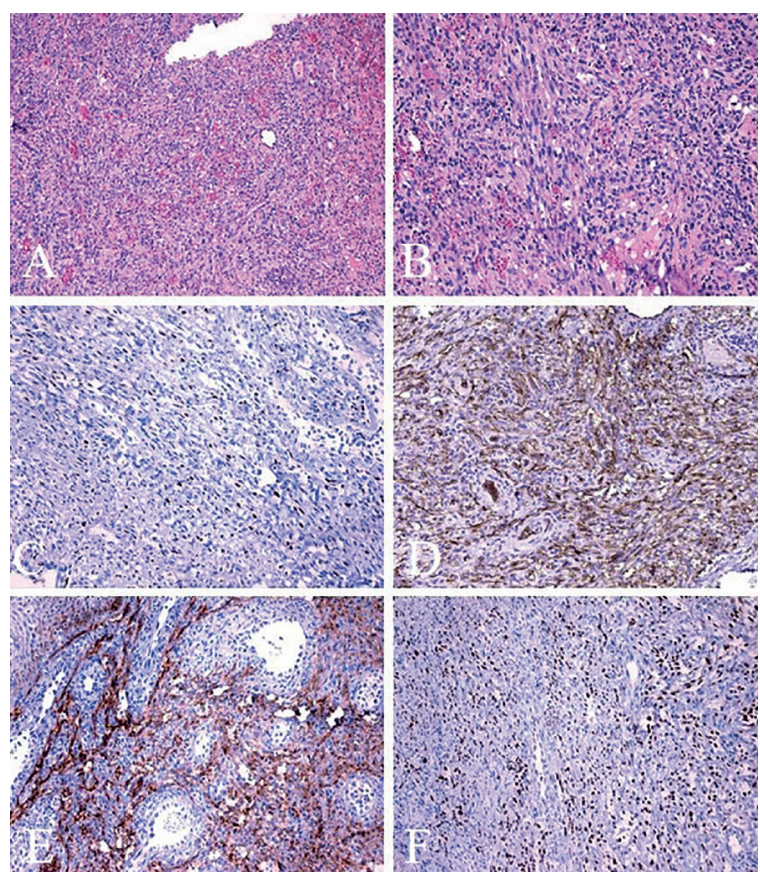

Fig. 2: Histopathological and immunohistochemistry analysis of oral KS. A) Proliferation of spindle cells intermixed with numerous congested blood vessels (H\&E, 100x). B) Spindle cells with significant pleomorphism and presence of blood-filled slits like spaces (H\&E, 200x). Immunohistochemistry reaction showing positivity for HHV-8 (DAB, 200x) (C), CD34 (DAB, 200x) (D), D2-40 (podoplanin) (DAB, 200x) (E) and Prox-1 (DAB, 200x) (F).
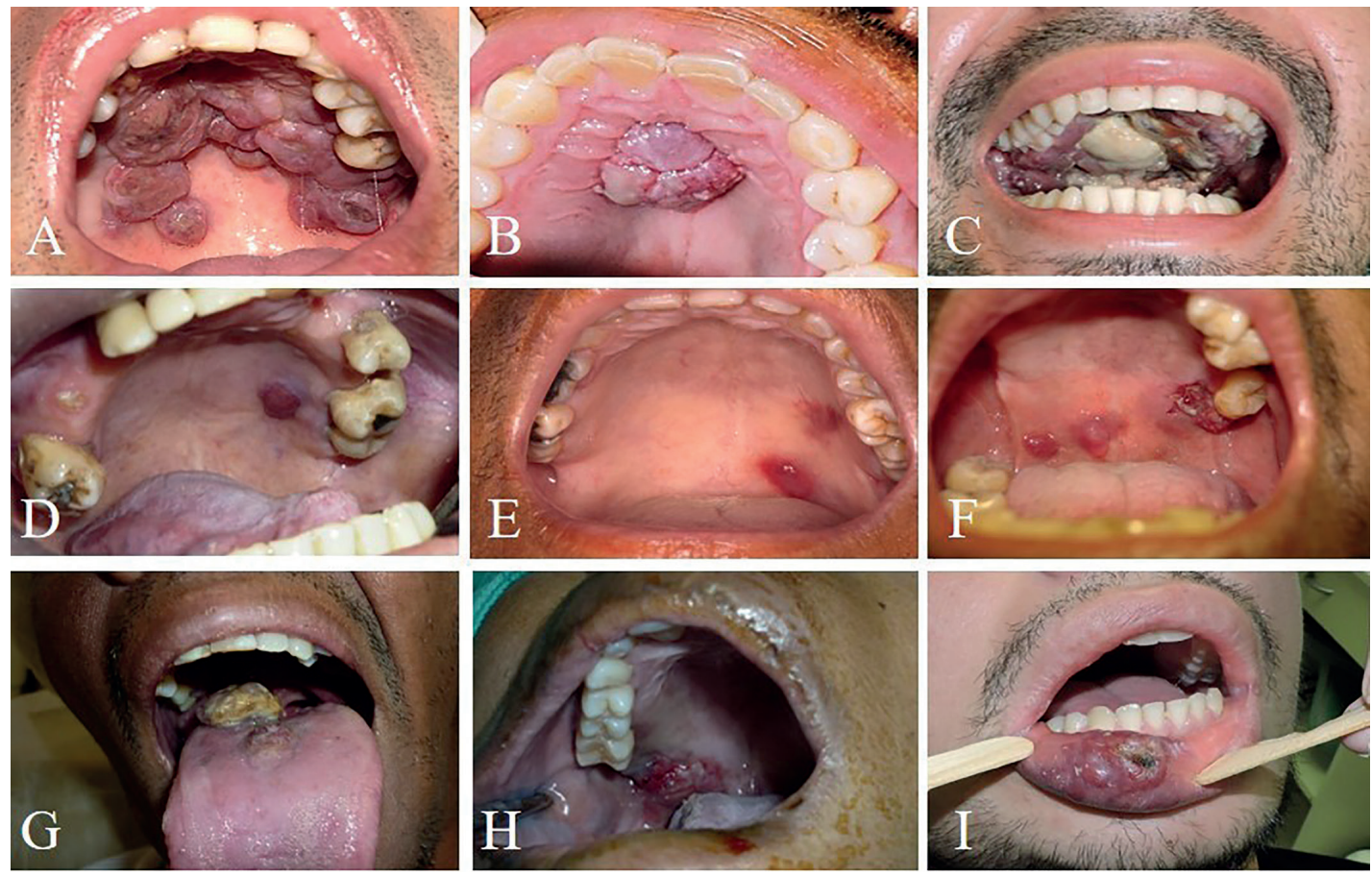

Fig. 1: Different clinical presentations of oral KS in the analysed patients. A) A 35-year-old male patient presented a painful swelling in the hard palate with superficial areas of necrosis. B) A 39-year-old male patient with a nodular lesion in the hard palate. C) A 31-year-old male patients demonstrated extensive bleeding and a necrotic lesion in the hard palate. D) A 58-yearold male patient presented a bleeding nodule in the hard palate. E) A 30-year-old male patient showed an asymptomatic purple spot in the hard palate. F) A 25-year-old male patient was presented with a necrotic lesion and bleeding in the hard palate associated with posterior teeth, as well as two nodules in the soft palate. G) A 23-year-old male patient demonstrated a bleeding and painful swelling in the posterior tongue with necrotic areas. H) A 41-year-old male patient was referred with an ulcerated swelling in the hard palate. I) A 25-year-old male patient presented with a painful and ulcerated lesion in the lower lip. 
Laboratory findings of patients who presented oral KS evidenced a mean HVL of $149,487.6$ copies/mL (range of 0-1,556,502 copies/mL), mean CD4L count of 155.9 cells/mm3 (range of $2-837$ cells $/ \mathrm{mm} 3$ ), mean CD8L count of 944.8 cells $/ \mathrm{mm} 3$ (range of 143-3056 cells/ $\mathrm{mm} 3$ ) and mean CD4L/CD8L of 0.17 cells/mm3 (range of $0.01-0.70$ cells $/ \mathrm{mm} 3)$. The control group showed a mean HVL of 592,295.6 copies/mL (range of 69$6,254,071$ copies/mL), mean CD4L count of 112.5 cells/ mm3 (range of 10-540 cells/mm3), mean CD8L count of 996.6 cells $/ \mathrm{mm} 3$ (range of $229-4557$ cells $/ \mathrm{mm} 3$ ) and mean CD4L/CD8L count of 0.16 cells $/ \mathrm{mm} 3$ (range of $0.01-0.57$ cells $/ \mathrm{mm} 3$ ) (Table 1 ).

Statistical analysis evidenced by the Poisson regression test for prevalence analysis that HVL (HR 95\% CI: 1.6517 [1.4681-4.2033]; $p<0.0001$ ), CD4L (HR 95\% CI: 2.8058 [0.0667-8.5103]; $p<0.0001)$ and CD4L/CD8L ratio (HR 95\% CI: 1.7613 [0.7740-2.1304]; $p<0.0001$ ) were significantly associated with oral KS development (Table 2).

Table 1: Laboratory findings of the analysed patients.

\begin{tabular}{|c|c|c|c|c|c|c|c|c|}
\hline & \multicolumn{4}{|c|}{ Oral KS } & \multicolumn{4}{|c|}{ Control group } \\
\hline & $\begin{array}{l}\text { HIV Viral } \\
\text { load (cop- } \\
\text { ies/mL) }\end{array}$ & $\begin{array}{c}\text { CD4+ } \\
\left(\text { cells } / \mathbf{m m}^{3}\right)\end{array}$ & $\begin{array}{c}\text { CD8+ } \\
\left(\text { cells } / \mathbf{m m}^{3}\right)\end{array}$ & $\begin{array}{c}\text { CD4+/ } \\
\text { CD8+ (ce- } \\
\left.\text { lls/mm } / \mathbf{m m}^{3}\right)\end{array}$ & $\begin{array}{l}\text { HIV Viral } \\
\text { load (cop- } \\
\text { ies/mL) }\end{array}$ & $\begin{array}{l}\text { CD4+ (ce- } \\
\left.\text { lls } / \mathbf{m m}^{3}\right)\end{array}$ & $\begin{array}{l}\text { CD8+ (ce- } \\
\left.\text { lls/mm } \text { mm }^{3}\right)\end{array}$ & $\begin{array}{c}\text { CD4+/ } \\
\text { CD8+ (ce- } \\
\left.\text { lls/mm } \text { m }^{3}\right)\end{array}$ \\
\hline Case 1 & 91442 & 216 & 1399 & 0.15 & ND & 185 & 741 & 0.25 \\
\hline Case 2 & 232 & 131 & 1186 & 0.11 & 101 & 158 & 524 & 0.30 \\
\hline Case 3 & 156799 & 179 & 1788 & 0.10 & 4751 & 93 & 995 & 0.09 \\
\hline Case 4 & 233346 & 103 & 1296 & 0.08 & 205 & 209 & 1635 & 0.13 \\
\hline Case 5 & 0 & 71 & 410 & 0.17 & 616182 & 121 & 2134 & 0.06 \\
\hline Case 6 & 2495 & 101 & 1208 & 0.08 & 50024 & 540 & 1206 & 0.45 \\
\hline Case 7 & 144680 & 91 & 882 & 0.10 & 598890 & 19 & 257 & 0.07 \\
\hline Case 8 & 505865 & 31 & 652 & 0.05 & 478 & 98 & 312 & 0.31 \\
\hline Case 9 & 28988 & 57 & 789 & 0.07 & 587462 & 19 & 925 & 0.02 \\
\hline Case 10 & 402 & 379 & 600 & 0.63 & 3242533 & 155 & 586 & 0.26 \\
\hline Case 11 & 1556502 & 142 & 1593 & 0.09 & 6488 & 57 & 229 & 0.25 \\
\hline Case 12 & 289329 & 15 & 500 & 0.03 & 67783 & 10 & 229 & 0.04 \\
\hline Case 13 & $>500000$ & 123 & 655 & 0.19 & 6254071 & 163 & 4557 & 0.04 \\
\hline Case 14 & 53298 & 23 & 1313 & 0.02 & 11396 & 57 & 877 & 0.06 \\
\hline Case 15 & $>500000$ & 2 & 227 & 0.01 & 8859 & 103 & 570 & 0.18 \\
\hline Case 16 & 323026 & 5 & 200 & 0.03 & 24143 & 113 & 1242 & 0.09 \\
\hline Case 17 & 3916 & 71 & 672 & 0.11 & 49970 & 50 & 1543 & 0.03 \\
\hline Case 18 & 21395 & 674 & 3056 & 0.22 & 312211 & 35 & 275 & 0.13 \\
\hline Case 19 & 121334 & 99 & 455 & 0.22 & 114701 & 85 & 1345 & 0.06 \\
\hline Case 20 & 72592 & 31 & 627 & 0.05 & 581167 & 18 & 758 & 0.02 \\
\hline Case 21 & 313784 & 30 & 536 & 0.06 & 1629621 & 168 & 1150 & 0.15 \\
\hline Case 22 & 162098 & 143 & 559 & 0.26 & 259 & 109 & 2067 & 0.05 \\
\hline Case 23 & 0 & 837 & 1445 & 0.58 & 327000 & 12 & 1200 & 0.01 \\
\hline Case 24 & 137 & 380 & 1178 & 0.32 & 131519 & 216 & 2097 & 0.10 \\
\hline Case 25 & 101999 & 82 & 559 & 0.15 & 11025 & 28 & 259 & 0.11 \\
\hline Case 26 & 1211 & 340 & 1355 & 0.25 & 9107 & 151 & 526 & 0.29 \\
\hline Case 27 & 4359 & 11 & 853 & 0.01 & 1803218 & 66 & 504 & 0.13 \\
\hline Case 28 & 5708 & 200 & 1741 & 0.11 & 70272 & 196 & 343 & 0.57 \\
\hline Case 29 & 248412 & 59 & 599 & 0.10 & 663068 & 64 & 522 & 0.12 \\
\hline Case 30 & 0 & 66 & 913 & 0.07 & 69 & 78 & 292 & 0.27 \\
\hline Case 31 & 41006 & 199 & 845 & 0.24 & - & - & - & - \\
\hline Case 32 & 273 & 100 & 143 & 0.70 & - & - & - & - \\
\hline
\end{tabular}

Table 2: Poisson regression analysis.

\begin{tabular}{|l|c|c|}
\hline Laboratory findings & HR $(\mathbf{9 5 \%}$ CI) & P-value \\
\hline HIV viral load & $1.6517(1.4681-4.2033)$ & $<0.0001$ \\
\hline CD4+ & $2.8058(0.0667-8.5103)$ & $<0.0001$ \\
\hline CD8+ & $2.4227(1.2668-7.0260)$ & 0.3818 \\
\hline CD4+/CD8+ & $1.7613(0.7740-2.1304)$ & $<0.0001$ \\
\hline
\end{tabular}




\section{Discussion}

Clinical and pathological information regarding oral $\mathrm{KS}$ is still very limited due to the diverse clinical presentation and because lesions are mostly presented in late manifestation of HIV/AIDS $(4,11,19)$. The complete aetiopathogeneses of oral KS remains unclear, although HHV-8 represents the main etiological agent (20). The patient's immune system is evaluated by laboratory analysis of HVL, CD4L, CD8L and the CD4L/CD8L ratio, and their influence on clinical disease manifestation has been widely discussed $(3,21)$. Thus, the objective of the study was to correlate HVL, CD4L, CD8L and the CD4L/CD8L ratio and their influence on oral KS development.

Clinically, oral KS demonstrated a male predominance, similar to previous literature $(5,16)$. The lesions were most commonly presented in young patients and rarely affect elderly individuals, despite the increase in HIV/ AIDS infection and the incidence of oral KS in patients aged 50 and over (22). When presented in the oral cavity, $\mathrm{KS}$ is most frequently diagnosed in the hard and soft palate $(2,11)$. Oral tumours may present a wide diversity of presentations, varying from single spots to bleeding, painful and necrotic swellings $(2,19)$. They also may present colour alteration in the buccal mucosa due to their angiogenic origin, ranging from red to purple lesions $(5,7,8,19)$.

The systemic affliction of HIV/AIDS patients generally causes, besides the oral cavity, development of $\mathrm{KS}$ in the skin, gastrointestinal and respiratory complex, consistent with the findings of the present study (22). Systemic conditions commonly associated with immunocompromised patients were also observed, including oral presentation of oral candidiasis and herpes simplex, as well as systemic diseases including tuberculosis, pneumonia, gastroenteritis, syphilis and meningitis $(6,18,19)$.

Medical follow-ups of PLWHA generally involve a multidisciplinary assessment based on laboratory findings, including HVL, CD4L, CD8L and CD4L/CD8L, and other complementary exams when necessary $(23,24)$. However, an increase in the number of reports of oral $\mathrm{KS}$ as the first manifestation of HIV/AIDS has been shown, consistent with the findings of our study that $71.8 \%$ of patients showed oral lesions as the first manifestation of the disease $(16,17)$.

Thus, laboratory exams may be presented as a good option to evaluate patients' systemic condition $(8,10,15)$. The goal of this study was to explore the association of HVL, CD4L, CD8L and CD4L/CD8L ratio and oral KS development compared with a control group with no lesions on the body. Interestingly, HVL, CD4L and CD4L/CD8L ratio showed significant results when compared with the control group, demonstrated significant weight of the association of these variables with
KS development. Rezende et al. (25) observed a relationship of HVL with AIDS-related KS, resulting in a significant relationship of HVL and upper gastrointestinal KS, consistent with our findings. Many studies have explored the association of CD4L cell count with AIDSrelated KS, and they showed a significant correlation of KS development when a CD4L $\leq 200$ cells $/ \mathrm{mm} 3$ was observed, similar to our results $(26,27)$. In addition, Poizot-Martin et al. (26) reported that a CD4L/CD8L $\leq 0.5$ increased the risk of development of KS, corroborating our results as we showed a significant higher probability of developing oral KS with altered CD4L/ CD8L levels. Hence, the clinical significance of HVL, CD4L count and the $\mathrm{CD} 4 \mathrm{~L} / \mathrm{CD} 8 \mathrm{~L}$ ratio is noteworthy in the development of oral KS.

More recently, KS genomics has gained attention over the past decades due to its remarkable pathogenic mechanisms. The association of the HHV-8 genome and KS development has been explored worldwide (27). It has been shown that more than 80 genes are expressed in the regulated transcriptional program that promotes latency with very limited viral expression or supports lytic replication with the production of progeny virions $(28,29)$. The cellular tropism of HHV-8 in KS includes epithelial, endothelial and B cells and more recently has been expanded to include neurons $(29,30)$.

The present study showed a significant result of oral KS development and its association with HVL, CD4L count and the CD4L/CD8L ratio. Despite the limitations on the number of patients to validate the current results, this is the first study to explore laboratory findings and oral KS development as an alternative method to improve diagnostic accuracy. Additionally, knowledge of the influence of other etiologic factors is important to better establish the etiopathogenesis and pathogenesis of the disease, as well as to determine the gene alterations related to KS development.

\section{References}

1. Semango GP, Charles RM, Swai CI, Mremi A, Amsi P, Sonda T, et al. Prevalence and associated risk factors for Kaposi's sarcoma among HIV-positive patients in a referral hospital in Northern Tanzania: a retrospective hospital-based study. BMC Cancer. 2018;18:1258. 2. Agaimy A, Mueller SK, Harrer T, Bauer S, Thompson LDR. Head and neck Kaposi sarcoma: clinicopathological analysis of 11 cases. Head Neck Pathol. 2018;12:511-6.

3. Bhutani M, Polizzotto MN, Uldrick TS, Yarchoan R. Kaposi sarcoma-associated herpesvirus-associated malignancies: epidemiology, pathogenesis, and advances in treatment. Semin Oncol. 2015;42:223-46.

4. Benevenuto de Andrade BA, Ramírez-Amador V, Anaya-Saavedra G, Martínez-Mata G, Fonseca FP, Graner E, et al. Expression of PROX-1 in oral Kaposi's sarcoma spindle cells. J Oral Pathol Med. 2014;43:132-6.

5. Garzino-Demo P, Mettus A, Passalacqua F, Vittone F, Ramieri G. Oral localization of Kaposi sarcoma: clinical presentation and conservative management. J Craniofac Surg. 2017;28:e545-e7.

6. Gupta K, Tun A, Gupta A, Berkowitz LB, Anwar R, Liu Y, et al. A case of classic Kaposi sarcoma in an immunocompetent human im- 
munodeficiency virus-negative Dominican man. SAGE Open Med Case Rep. 2020;8:2050313X20938249.

7. Khammissa RA, Pantanowitz L, Feller L. Oral HIV-associated Kaposi sarcoma: a clinical study from the Ga-Rankuwa area, South Africa. AIDS Res Treat. 2012;2012:873171.

8. Pantanowitz L, Khammissa RA, Lemmer J, Feller L. Oral HIVassociated Kaposi sarcoma. J Oral Pathol Med. 2013;42:201-7.

9. Sullivan RJ, Pantanowitz L, Casper C, Stebbing J, Dezube BJ. HIV/AIDS: epidemiology, pathophysiology, and treatment of Kaposi sarcoma-associated herpesvirus disease: Kaposi sarcoma, primary effusion lymphoma, and multicentric Castleman disease. Clin Infect Dis. 2008;47:1209-15.

10. Solivetti FM, Elia F, Latini A, Cota C, Cordiali-Fei P, Di Carlo A. AIDS-Kaposi Sarcoma and Classic Kaposi Sarcoma: are different ultrasound patterns related to different variants? J Exp Clin Cancer Res. 2011;30:40.

11. de Carvalho WRS, de Souza LL, Pontes FSC, Uchôa DCC, Corrêa DL, de Cáceres CVBL, et al. A multicenter study of oral sarcomas in Brazil. Oral Dis. 2020;26:43-52.

12. Dai L, Qin Z, Defee M, Toole BP, Kirkwood KL, Parsons C. Kaposi sarcoma-associated herpesvirus (KSHV) induces a functional tumor-associated phenotype for oral fibroblasts. Cancer Lett. 2012;318:214-20.

13. Lepone LM, Rappocciolo G, Piazza PA, Campbell DM, Jenkins FJ, Rinaldo CR. Regulatory T cell effect on CD8+ T cell responses to human herpesvirus 8 infection and development of Kaposi's sarcoma. AIDS Res Hum Retroviruses. 2017;33:668-74.

14. Robey RC, Lagos D, Gratrix F, Henderson S, Matthews NC, Vart $\mathrm{RJ}$, et al. The CD8 and CD4 T-cell response against Kaposi's sarcoma-associated herpesvirus is skewed towards early and late lytic antigens. PLoS One. 2009;4:e5890.

15. Park LS, Hernández-Ramírez RU, Silverberg MJ, Crothers K, Dubrow R. Prevalence of non-HIV cancer risk factors in persons living with HIV/AIDS: a meta-analysis. AIDS. 2016;30:273-91.

16. Dubrow R, Qin L, Lin H, Hernández-Ramírez RU, Neugebauer RS, Leyden W, et al. Association of CD4+ T-cell count, HIV-1 RNA viral load, and antiretroviral therapy with Kaposi sarcoma risk among HIV-infected persons in the United States and Canada. J Acquir Immune Defic Syndr. 2017;75:382-90.

17. Crum-Cianflone NF, Hullsiek KH, Ganesan A, Weintrob A, Okulicz JF, Agan BK. Infectious Disease Clinical Research Program HIV Working Group. Is Kaposi's sarcoma occurring at higher CD4 cell counts over the course of the HIV epidemic?. AIDS. 2010;24:2881-3. 18. Taiwo OO, Hassan Z. The impact of Highly Active Antiretroviral Therapy (HAART) on the clinical features of HIV-related oral lesions in Nigeria. AIDS Res Ther. 2010;7:19.

19. Guedes PTL, Pontes FSC, Prado-Ribeiro AC, Rodrigues-Oliveira L, Brandão TB, de Souza LL, et al. HIV Positive Patients with oral Kaposi's Sarcoma: An Overall Survival Analysis Of 31 Patients. Oral Surg Oral Med Oral Pathol Oral Radiol. 2021;131:702-10.

20. Little RF, Uldrick TS. Are there clues to oral Kaposi sarcomaassociated herpesvirus shedding and Kaposi sarcoma oncogenesis in the oral microbiome? J Infect Dis. 2020;221:1226-28.

21. Volkow P, Cesarman-Maus G, Garciadiego-Fossas P, RojasMarin E, Cornejo-Juárez P. Clinical characteristics, predictors of immune reconstitution inflammatory syndrome and long-term prognosis in patients with Kaposi sarcoma. AIDS Res Ther. 2017;14:30. 22. Speicher DJ, Wanzala P, D'Lima M, Njiru A, Chindia M, Dimba $\mathrm{E}$, et al. Diagnostic challenges of oral and cutaneous Kaposi's sarcoma in resource-constrained settings. J Oral Pathol Med. 2015;44:842-

23. Gonçalves PH, Uldrick TS, Yarchoan R. HIV-associated Kaposi sarcoma and related diseases. AIDS. 2017;31:1903-16.

24. Goncalves PH, Ziegelbauer J, Uldrick TS, Yarchoan R. Kaposi sarcoma herpesvirus-associated cancers and related diseases. Curr Opin HIV AIDS. 2017;12:47-56

25. Rezende RE, Kahwage RL, da Costa TV, Machado AA, Brunaldi MO, Kemp R, et al. Upper gastrointestinal Kaposi's sarcoma in HIV-infected patients: ten years of endoscopy observation at a single
Brazilian center. Int J Infect Dis. 2015;39:110-5. 26. Poizot-Martin I, Lions C, Cheret A, Rey D, Duvivier C, Jacomet $\mathrm{C}$, et al. Kaposi sarcoma in people living with HIV: incidence and associated factors in a French cohort between 2010 and 2015. AIDS. 2020;34:569-77.

27. Dupont C, Vasseur E, Beauchet A, Aegerter P, Berthé H, de Truchis $\mathrm{P}$, et al. Long-term efficacy on Kaposi's sarcoma of highly active antiretroviral therapy in a cohort of HIV-positive patients. CISIH 92. Centre d'information et de soins de l'immunodéficience humaine. AIDS. 2000;14:987-93.

28. Zhang P, Wang J, Zhang X, Wang X, Jiang L, Gu X. Identification of AIDS-associated Kaposi sarcoma: a functional genomics approach. Front Genet. 2020;10:1376.

29. Veettil MV, Bandyopadhyay C, Dutta D, Chandran B. Interaction of KSHV with host cell surface receptors and cell entry. Viruses. 2014;6:4024-46.

30. Uppal T, Banerjee S, Sun Z, Verma SC, Robertson ES. KSHV LANA - the master regulator of KSHV latency. Viruses. 2014;6:4961-98.

\section{Funding}

None declared.

\section{Conflict of interest}

The authors declare they have no conflict of interest.

\section{Ethics}

We received the consent of each patient to participate in the present study. The ethics committee of the João de Barros Barreto University Hospital approved this work (No. 3.952.288).

\section{Authors contributions}

Conception and design: RHAS, ACPR, TBB, MAL, ARSS, JCM, OPA, FSCP and HARP.

Provision of study materials and/or patients: RHAS, BWGA, JCM, TTG, FSCP and HARP.

Data collection and assembly: RHAS, LLS, PTLG, ACPR, LRO, TBB, BWGA, MAL, ARSS, FSCP and HARP.

Data analyses and interpretation: RHAS, LLS, TTG, FSCP and HARP.

Manuscript writing: RHAS, LLS, FSCP and HARP

Final approval of manuscript: The final version of this manuscript has been approved by all authors. 